\title{
Experience Design for Work Tools
}

\author{
Virpi Roto \\ Aalto University, School of Arts, Design and Architecture, Espoo, Finland \\ virpi.roto@aalto.fi
}

\begin{abstract}
This workshop paper approaches the topic of user experience at work from the perspective of designing work tools with a specific user experience (UX) as a goal. To demonstrate the different design approaches towards addressing the three time spans of user experience - momentary, episodic, and long-term examples of related research areas are briefly introduced, as well as their deployment in work context. The concept of experience goal has been found useful in addressing the different time spans, but it is often hard for designer to define momentary experience goals due to the fleeting nature of momentary emotions.
\end{abstract}

\section{Keywords}

Experience Design · Work tools · User experience · Time spans

\section{Introduction}

Experience is a broad and multidisciplinary research topic. User experience research as one of the experience research fields has become highly popular during this millennium, even so that it dominates in volume the experience publications of all disciplines. There are several subfields that approach design for user experiences from different perspectives, such as affective computing, interaction aesthetics, gamification, positive design, etc. However, only a small

How to cite this book chapter:

Roto, V. 2020. Experience Design for Work Tools. In: Loizides, F., Winckler, M., Chatterjee, U., Abdelnour-Nocera, J. and Parmaxi, A. (eds.) Human Computer Interaction and Emerging Technologies: Adjunct Proceedings from the INTERACT 2019 Workshops. Pp. 145-150. Cardiff : Cardiff University Press. DOI: https://doi. org/10.18573/book3.r. License: CC-BY 4.0. 
minority of this research is done in work contexts. This paper very briefly introduces and compares these design approaches, categorizing them into the user experience time spans - momentary, episodic, and long-term [12] - especially from the perspective of designing for experiences in the workplace through the interactive systems used at work.

\section{Momentary user experience}

Affective Computing refers to computing that relates to, arises from, or deliberately influences emotions [9]. The goal of affective computing is to build an affect model that enables an interactive system provide users intelligent, sensitive and friendly responses that match users' affective state. Affective computing research has been expanding with the boom of sensors and artificial intelligence, and new terms such as artificial emotional intelligence [14] are emerging. This line of research is based on emotion recognition and the goal is to make computers, such as social robots and other conversational agents, to express emotions in similar ways as humans. With its focus on affect and emotion, this research area contributes to user experience from a momentary perspective.

While affective computing has often been implemented into consumer systems such as chatbots on commercial web sites, there has been less research on its applications at workplaces. Conversational agents have arrived to workplaces, but it is not easy to find scientific publications on deploying affective conversational agents at work context.

\section{Episodic user experience}

Games are perhaps the best example of episodic user experiences. There is a plot in game design that aims to produce emotional episodes with excitement, disappointment, fun, reward, etc. After the game-over, the gamer evaluates her/his success as one episode. Naturally, there are various kinds of games, but it is hard to think about a game that would not consist of some kind of emotional episodes. While workplace is not a context targeted at having fun, gamification features have been adopted by many work related systems, as a recent literature review shows [15].

Most activities at work are episodic, i.e., tasks with a clear start and end point, and the interactive tools at work are often designed as stepwise user interfaces, e.g., wizards. With regards to work contexts, Zeiner have studied work experiences and identified 21 categories of positive experiences. From stories of pleasurable experiences at work, Zeiner et al. (2018) identified categories of meaningful episodes at work, such as Receiving feedback, Helping others, or Exchanging ideas. 


\section{Long-term user experience}

Following the basic idea of Positive Psychology, a design approach called Positive Design does not target at fixing problems, but instead, it focuses on designs that make life worth living [1]. Thus, Positive Design aims to address a long time span. While a sum of pleasurable momentary experiences contributes to overall wellbeing, Pleasure is just one of the three elements of the Positive Design Framework (PDF). The other two are Personal Significance, which is about pursuing personal goals and aspirations, and Virtue about being a morally good person (ibid.).

Another insightful article about the universal grounding for experience design beyond momentary fun [3], who tested how the psychological needs [13] relate to experiences with technology. The psychological needs that were especially salient included stimulation, relatedness, competence, and popularity. We have found this list highly inspiring in designing for experiences. Experience designers can think what and how to design in order to fulfill these needs either through momentary, episodic, or long-term experiences. This means that the designers should define not only functional but also experience goals to design for.

\section{Experience goals}

Our own research has taken place in work contexts, in which we have aimed to provide tools for designers who want to improve employee experience via interactive systems used at work. We have focused on the means to set experience goals [8] and to utilize those goals during design process 6,11 . Experience goal is defined as the intended momentary emotion or the meaningful relationship/bond that a person has with the designed product or service [4]. Therefore, it can address all time spans of user experience discussed above. In the collection of 20 experience goals from student design cases on our Experience-Driven Design class [7, p. 70], there are separate goals to address the three time spans. For example, one student team defined Wow as a momentary experience goal, Proudness as episodic, and Trust as a long-term goal.

But what is the relationship between the time-span-specific design approaches and experience goals? In the Affective Computing approach, a designer might not define experience goals per se, but the affect model defines the appropriate emotional response to a certain recognized affect. The designer then designs a verbal, gestural, or other response that matches the emotion suggested by the affect model.

In case of episodic experiences, the main experience goal is defined based on the wanted emotional state after the episode. Based on this main goal, different experience goals can be defined for the different phases of the episode plot. The 
plots in games are not always designed with a specific emotion in mind in each phase, but I see potential in improving episodic user experience by constructing an emotional plot for, e.g., an hour reporting task.

The frameworks provided for long-term experience design provide an inspirational basis for setting experience goals. In our research, we have utilized the basic psychological needs and found that in work context, Competence experience is clearly the most frequent experience goal.

We also studied the Positive Design Framework [1] and developed it further to provide more specific guidance for designing meaningful experiences in the workplace [5]. This PDFwork framework is, according to our knowledge, the only framework that provides a relatively solid starting point for experience design in the domain of work tools. While the main focus of PDF is longterm experience, the three elements seem to match the momentary (Pleasure), episodic (Personal Significance) and long-term (Virtue) time spans.

\section{Conclusion}

Our research on experience design targets at employee wellbeing by designing meaningful interactions with technology at work. In this endeavor, we have studied momentary, episodic, and long-term user experience goals. It may be difficult for the designer to set experience goals for momentary experiences in isolation, but there is high potential in defining experience goals for an episodic experience. Our work has mostly focused on the long-term, meaningful user experiences at work, for example, the PDFWork framework [5].

This workshop paper briefly described some of the emotional design approaches for each UX time span, and discussed how they can be addressed in experience goals defined for design. I hope this paper opens up a useful, less addressed design perspective to the workshop discussions on user experiences at work.

\section{References}

1. Desmet, P. M., \& Pohlmeyer, A. E. (2013). Positive design: An introduction to design for subjective well-being. International journal of design, 7(3).

2. Egger, F. N. (2001, June). Affective design of e-commerce user interfaces: How to maximise perceived trustworthiness. In Proc. Intl. Conf. Affective Human Factors Design (pp. 317-324).

3. Hassenzahl, M., Diefenbach, S., \& Göritz, A. (2010). Needs, affect, and interactive products-Facets of user experience. Interacting with computers, 22(5), 353-362.

4. Lu, Y., \& Roto, V. (2014, October). Towards meaning change: experience goals driving design space expansion. In Proceedings of the 8th Nordic 
Conference on Human-Computer Interaction: Fun, Fast, Foundational (pp. 717-726). ACM.

5. Lu, Y., \& Roto, V. (2015). Evoking meaningful experiences at work - a positive design framework for work tools. Journal of Engineering Design, 26(4-6), 99-120.

6. Lu, Y., \& Roto, V. (2016). Design for pride in the workplace. Psychology of Well-being, 6(1), 6.

7. Lu, Y. (2018). Experience goals in designing professional tools: evoking meaningful experiences at work. Aalto University publication series DOCTORAL DISSERTATIONS, 131/2018.

8. Kaasinen, E., Roto, V., Hakulinen, J., Heimonen, T., Jokinen, J. P., Karvonen, H., ... \& Tokkonen, H. (2015). Defining user experience goals to guide the design of industrial systems. Behaviour \& Information Technology, 34(10), 976-991.

9. Picard. R. W. (1997). Affective Computing. Cambridge, MA: The MIT Press.

10. Roto, V., Clemmensen, T., Väätäjä, H., \& Law, E. L. C. (2018). Designing interactive systems for work engagement. Human Technology, 14(2).

11. Roto, V., Kaasinen, E., Heimonen, T., Karvonen, H., Jokinen, J. P., Mannonen, P., ... \& Kymäläinen, T. (2017, May). Utilizing experience goals in design of industrial systems. In Proceedings of the 2017 CHI Conference on Human Factors in Computing Systems (pp. 6993-7004). ACM.

12. Roto, V., Law, E., Vermeeren, A. P. O. S., \& Hoonhout, J. (2011, September). User experience white paper: Bringing clarity to the concept of user experience. In Dagstuhl Seminar on Demarcating User Experience.

13. Sheldon, K. M., Elliot, A. J., Kim, Y., \& Kasser, T. (2001). What is satisfying about satisfying events? Testing 10 candidate psychological needs. Journal of personality and social psychology, 80(2), 325.

14. Schuller, D., \& Schuller, B. W. (2018). The age of artificial emotional intelligence. Computer, 51(9), 38-46.

15. Warmelink, H., Koivisto, J., Mayer, I., Vesa, M., \& Hamari, J. (2018). Gamification of the work floor: A literature review of gamifying production and logistics operations. 